\title{
Analysis of some parameters influencing moisture quantity measurements in wheat with NIR technique
}

\author{
Mirko Mesić, Venco Ćorluka, Zdravko Valter \\ Faculty of Electrical Engineering, University of Osijek, Croatia \\ Kneza Trpimira 2b, HR-31000 Osijek, E-mail: mirko.mesic@os.htnet.hr
}

\begin{abstract}
Water has an absorption band of four wavelengths, namely 1.2, 1.45, 1.94, and 2.94 micrometers, in the near-infrared light range. When a sample is irradiated with light of the above wavelengths, this sample will absorb light in accordance with its moisture content. As moisture content of wheat increased, reflectance from the wheat sample decreased, which indicates that water is a strong light absorber than a sandy wheat sample. When light hits a sample, several interactions can occur: specular reflectance, diffuse reflectance, absorption, transmittance, refraction and scattering. In this paper we try to find out influence of several interactions on accurate measurement for moisture wheat.
\end{abstract}

Key words: Near-Infrared, Moisture, Wheat, Sensor

\section{INTRODUCTION}

The basic principles underlying near infrared [NIR] analysis have been known for more than 100 years. Near infrared spectroscopy and the chemo metric approach of multivariate data analysis has been combined. The combination of these two very different disciplines has led to numerous applications in various fields of science and industry. Near infrared radiation are the electromagnetic waves in the wavelength region longer than the visible light wavelength, lying from $780 \mathrm{~nm}$ to $2500 \mathrm{~nm}$. This radiation is invisible to human eyes. It is equal to vibration or rotational energy of molecules. This phenomenon makes it possible to identify molecules Thus NIR region contains the chemical information $\mathrm{CH}, \mathrm{OH}$ and $\mathrm{NH}$ of the functional groups because they have the strongest absorption. The quantitative measurements of the chemical concentration in a material can be possible in this way. NIR spectrum also gives information about the physical properties of samples and it can be employed for the average magnitude particle estimation or e.g. for the determining of the biomass percent in the fermentation. In NIR part very complex motions occur but only with the mentioned groups like $\mathrm{C}-\mathrm{H}$, $\mathrm{N}-\mathrm{H}$ and $\mathrm{O}-\mathrm{H}$. It has been established that the water molecules particularly absorb electromagnetic radiation with the wavelength of 1200, 1450, 1940 and $2950 \mathrm{~nm}$, and explicitly with the wavelength of 1450 and $1940 \mathrm{~nm}$. Thus those ones for water are called absorbing and on the basis of absorption with these wavelengths the water content can be determined in thin foliages and granular substance structure. The Near-Infrared spectrum can be divided into two separate regions. These are: the wavelength range from $780-1,200 \mathrm{~nm}$, also referred to as the Herschel region, where silicon detectors are used; and the range between 1,100 and 2,500 $\mathrm{nm}$, where lead sulphide $(\mathrm{PbS})$ is used as the material in the detectors.

\section{MOISTURE METER AND MEASUREMENT}

The water is a very good absorber in NIR region and it is very convenient for the quantitative analyses. The three-atomic nonlinearly molecules $\left(\mathrm{H}_{2} \mathrm{O}\right)$ in any substances can perform very complex motions under the influence of NIR radiation for what they need energy taken from radiation. This absorption has been established wavelengths of 1200, 1450, 1940 and $2950 \mathrm{~nm}$, and especially it can be seen with 1450 and $1940 \mathrm{~nm}$. Those are the absorbing wavelengths of the water. The absorbing spectrometer capable for the work in NIR is the basis for the moisture meter, and the goal is to determine the ratio between the absorbed and all together emitted radiation by the source at the absorbing wavelength, 1940nm for example. Some NIR spectrums of the textile pattern 
with the different water quantity are measured, figure 1. On the ordinate is marked by $\mathrm{A}$ the ratio between the absorbed radiation and the overall emitted radiation by the source on the any given wavelength in the relative units.

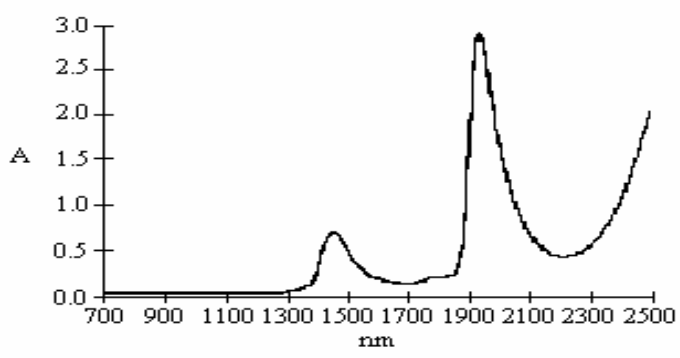

Fig. 1. Some NIR spectrums of the textile pattern with the different water quantity

By considering this ratio, it is necessary to (conclude) notice the relative moisture in the measuring substance i.e. in the sample. The material sample in which a part of moisture has to be determined can place between the source of IR radiation and detector. The absorption in the sample decreases the radiation that detector receive. The source can be dispersive or non-dispersive. If the radiation from the source is polychrome, it is into the narrow wave bands divided. The two different wavelengths are important for example. One is absorbing (1940nm) and the other reference wavelength $(1800 \mathrm{~nm})$. The transmission ratio for these different wavelengths is measured. The mechanism of the moisture meter is: a) generates near-infrared light using a tungsten lamp, b) using optical filters, creates a spectrum of the wavelengths that are absorbed by moisture and the wavelengths that are not absorbed by moisture, c) rotates the filters and irradiates the sample with the spectrum, d) measures the light reflected from the sample using a sensor, e) measures the amount of light reflection in the absorption wavelength range and in the reference wavelength range to get the ratio and calculate the absorbance $\left(A_{\lambda}\right)$ of the absorption wavelength range.

$$
A_{\lambda}=\log \frac{1}{R_{m \lambda}+R_{d \lambda}}
$$

$\mathrm{R}_{\mathrm{m} \lambda}$ - reflecting power called "reflectivity", $\mathrm{R}_{\mathrm{d} \lambda}$ - reflecting power caaled "reflectance"

In this works we are use a spectrometer with one ray, figure 2 . The numbers 1-7 marks as follows: 1 light source, 2 lens, 3 filter wheel, 4 mirror, 4 a absorption ray, 4b diffusion ray, 5 sample, 6 detector, 7 mirror. The simplest and cheapest NIR instruments are based on a limited number of band pass filters. These filters are chosen to represent the absorptions used for the most popular applications, e.g. protein, moisture and oil in agricultural samples. Diffuse scattered radiation is collected by the sphere mirror and focused on the detector.

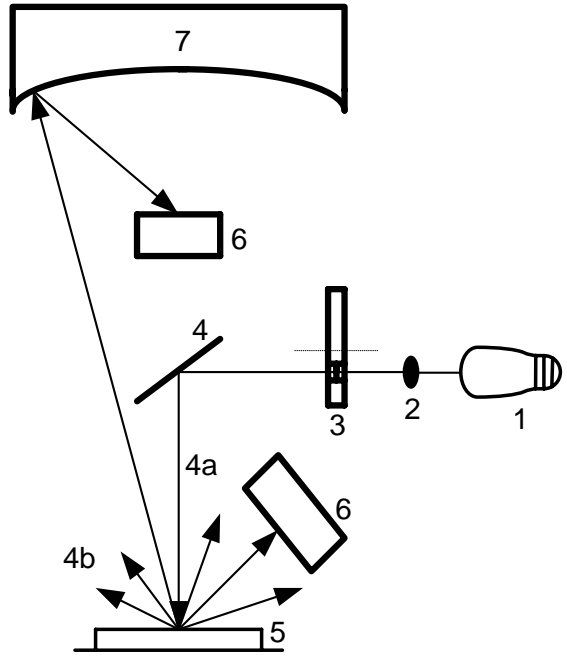

Fig. 2. Spectrometer with one ray

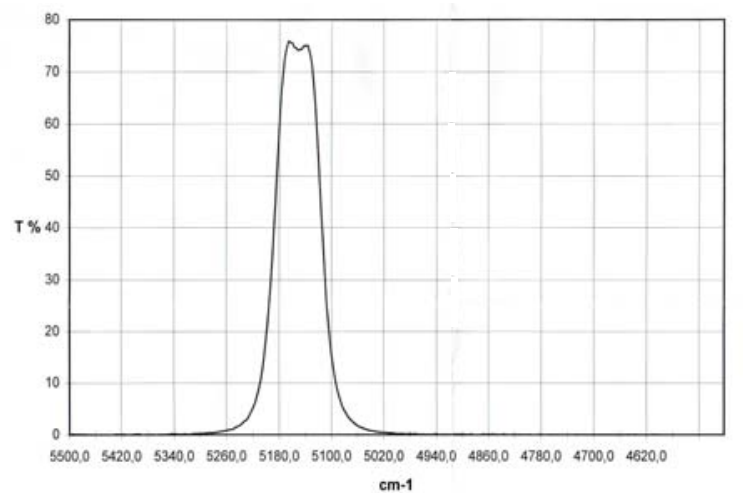

Fig. 3. Band pass filter for wavelength $1.94 \mu \mathrm{m}$

The resistance of the photoconductive detectors decreases with the input of IR light. The $\mathrm{PbS}$ photoconductive detector can be used for measuring of radiation wavelengths from $1000 \mathrm{~nm}$ to $3200 \mathrm{~nm}$. The major characteristics indicating IR detector performance are the photosensitivity, the noise equivalent power (NEP) and $\mathrm{D}^{*}$. The photosensitivity (in $\mathrm{V} / \mathrm{W}$ ) is the output voltage per input radiation power when is noise excluded. NEP is the quantity of input radiation power when the signal to noise ratio is 
1. Some noise may come from the infrared detector itself, from its operating circuits or from background fluctuation. However, under the assumption of the noise from an infrared detector and its circuits can be ignored in comparison with the noise caused by background fluctuation define NEP. In the many detectors, NEP is proportional to the square root of the detector active area. $\mathrm{D}^{*}$ in $\mathrm{cm} \cdot \mathrm{Hz}^{0,5} / \mathrm{W}$ or susceptibility is the photosensitivity per unit active area of a detector and makes it easier to compare the characteristics of different detectors.

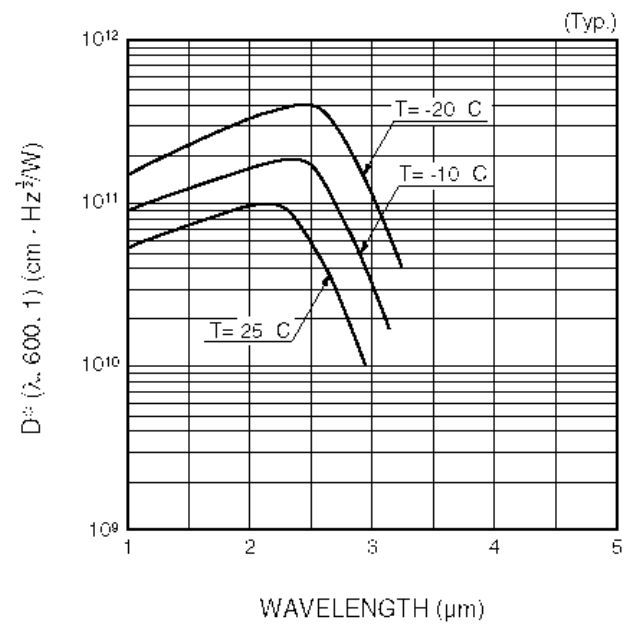

Fig. 4. Spectral response of a $\mathrm{PbS}$ detector

The small energy of the IR radiation is a special problem in comparison with visible and UV rays, for example $1.24 \mathrm{eV}$ at $1000 \mathrm{~nm}$ and $0.12 \mathrm{eV}$ at $10000 \mathrm{~nm}$. However, the IR detection efficiency can increase by the detector cooling. The spectral response curves of $\mathrm{PbS}$ photoconductive detectors are shift to the longer wavelength side at the same time. The spectral responses one $\mathrm{PbS}$ detector is on the Fig. 4. shown. For example, its highest susceptibility at temperature of $25^{\circ} \mathrm{C}$ lies at $2200 \mathrm{~nm}$ and it can increase at $-20^{\circ} \mathrm{C}$ to $2500 \mathrm{~nm}$. The time response of $\mathrm{PbS}$ photoconductive detectors becomes slower when cooling these but it is not essential for this moisture detector. The output signal from a detector is generally quite small and has to amplify. The preamplifier impedance has to be appropriate in consideration of the detector, low noise and bandwidth. So, the incident light is modulated by the luminous chopper, it is needed to use a tuned amplifier in reducing the noise. In addition, it is practical to cool amplifier with the detector together. The mark $\mathrm{T}$ on the ordinate in Fig. 4. represents the omitted ray's transmission in \%, and the abscissa contains the wave number data the magnitude, which is particularly introduced in IR region. It is equal to reciprocal of one wavelength and it is given in $\mathrm{cm}^{-1}$. With of the omitted band along one of the water absorption wavelengths can be seen in that figure.

\section{Result of measurement}

Results in table below says that relations between absorbance at $1940 \mathrm{~nm}$ and $1800 \mathrm{~nm}$ has value 1,31 and that means multiple with factor $\mathrm{k}=10$ given about $13,1 \%$ moisture.

Table 1. Results for $13,1 \%$ moisture

\begin{tabular}{|r|r|r|r|r|r|r|}
\hline \multicolumn{2}{|c|}{$\mathrm{Rm}$} & \multicolumn{2}{|c|}{$\mathrm{Rd}$} & $\mathrm{A} 1$ & $\mathrm{~A} 2$ & $\mathrm{MD}$ \\
\hline $1940 \mathrm{~nm}$ & $1800 \mathrm{~nm}$ & $1940 \mathrm{~nm}$ & $1800 \mathrm{~nm}$ & $1940 \mathrm{~nm}$ & $1800 \mathrm{~nm}$ & $\mathrm{~A} 1 / \mathrm{A} 2$ \\
\hline 6,25 & 20,91 & 0,714 & 2,209 & 2,157 & 1,636 & 1,318 \\
\hline 7,058 & 23,1 & 0,635 & 1,947 & 2,151 & 1,636 & 1,314 \\
\hline 5,729 & 21,15 & 0,575 & 1,976 & 2,2 & 1,635 & 1,345 \\
\hline 5,903 & 20,67 & 0,595 & 2,005 & 2,187 & 1,644 & 1,33 \\
\hline 6,076 & 20,79 & 0,674 & 2,034 & 2,171 & 1,641 & 1,322 \\
\hline
\end{tabular}

In this table we have reflections values for both wavelength and with that we make moisture determination value on basis Table 1 . Whit factor $\mathrm{k}=10$ like in Table 1, we got moisture 14,1\%.

Table 2. Results for $14,1 \%$ moisture

\begin{tabular}{|r|r|r|r|r|r|r|}
\hline \multicolumn{2}{|c|}{$\mathrm{Rm}$} & \multicolumn{2}{c|}{$\mathrm{Rd}$} & $\mathrm{A} 1$ & $\mathrm{~A} 2$ & $\mathrm{M}$ \\
\hline $1940 \mathrm{~nm}$ & $1800 \mathrm{~nm}$ & $1940 \mathrm{~nm}$ & $1800 \mathrm{~nm}$ & $1940 \mathrm{~nm}$ & $1800 \mathrm{~nm}$ & $\mathrm{~A} 1 / \mathrm{A} 2$ \\
\hline 4,861 & 22,115 & 0,635 & 2,442 & 2,259 & 1,609 & 1,403 \\
\hline 5,382 & 23,317 & 0,655 & 2,325 & 2,219 & 1,592 & 1,394 \\
\hline 4,661 & 24,519 & 0,694 & 2,5 & 2,255 & 1,568 & 1,418 \\
\hline 5,034 & 23,557 & 0,674 & 2,442 & 2,243 & 1,585 & 1,415 \\
\hline 5,208 & 24,039 & 0,714 & 2,616 & 2,227 & 1,574 & 1,41 \\
\hline
\end{tabular}

Wavelengths $1940 \mathrm{~nm}$ and $1800 \mathrm{~nm}$ were used to calculate moisture determination ratio (MD) for measuring moisture content of a wheat sample. $A_{1}$ is absorbance at $1940 \mathrm{~nm}$ and $A_{2}$ is absorbance at 1800 nm.

\section{CONCLUSION}

The thickness of the sample, which is convenient for a successful moisture measurement, depends on the sample structure and on the wavelength band that is by the source emitted. E.g. for the moisture measurement in NIR spectrum region between $1800 \mathrm{~nm}$ and $2500 \mathrm{~nm}$, the sample thickness has to be 
about $1 \mathrm{~mm}$. In the wavelength measurement region less than $1300 \mathrm{~nm}$ thanks to less absorption, the sample thickness can be about $5 \mathrm{~cm}$. The stronger source of NIR radiation also enables the longer path of the measuring electromagnetic rays so the maximal sample thickness depends on the instrument design. The less transmission paths are for the solid substances moisture measurement needed and it is more convenient to apply the reflection procedure from the surface. Then the moisture is by the calculation of the ratio between the radiations around the two different wavelengths determined. One that is absorbing for water and the other, which is not absorbing. The surface of the sample must be characteristic for the observed material, and the system has to calibrate separately for each material. The moisture concentrations from $0.02 \%$ to $100 \%$ can be in that way measured. In the case of the mirroring reflection, this procedure cannot use. The following effects emerge in the applications for the measuring of the granulated samples: the mirroring reflection, the total absorption and the diffuse reflection/absorption. The contribution of these effects separately depends on the structure and

\section{REFERENCES}

[1] Ćorluka, V.; Filić, M.; Mesić, M.; Valter, Z.: Near Infrared based Moisture Meter, 46th Internat.

Symposium ELMAR'04, Zadar/Croatia, 2004, Proceedings, p. 412-417.

[2] Ćorluka, V.; Filić, M.; Mesić, M.; Valter, Z.:

Optoelectronic Moisture Measurement, 3rd DAAAM International Conference ATDC'04, Split/Croatia, 2004, Proceedings p. 303-308.

[3] Ćorluka, V.; Filić, M.; Valter, Z.: Development of one Infrared Moisture Meter, 15th Internat. DAAAM Symposium, Vienna/Austria, 2004, Proceedings, p. 081-082.

[4] Günzler, H.; Gremlich, H.-U.: IR-Spektroskopie, Wiley-VCH Verlag, Weinheim, 2003

[5] Leschnik, W.: Feuchtemessung an Baustoffen Zwischen Klassik und Moderne, Feuchtetag '99,

Berlin, 1999, DGZfP-Proceedings BB 69-h2

[6] Büscher, K. A.; Wild, W.; Wiggenhauser, H.:

Feuchtemessung mit infraoptischen Methoden,

Feuchtetag '99, Berlin, 1999, DGZfP-Proceedings

BB 69-m2

[7] Geladi, P.; Dabbak, E.: An overview of chemometrics applications in near infrared spectrometry, Journal of Near Infrared Spectroscopy, 3(3), 1995, 119-132

[8] B.G. Osborne, T. Fearn, P.H. Hindle, Practical NIR Spectroscopy, Longman, Harlow, 49-78, 1993. granules size of the sample. With the large granules, the internal reflections occur and it can particularly complicate the measurement. The determining of the functional dependence of Moisture content $\%=\mathrm{f}$ (Absorbance)\% which is typical for every substance is included into the experimental phase along with the corresponding application of the moisture meter working by using the gravimetric procedure for the calibration. It has to establish before and must be stored in NIR moisture meter memory. The major limitation of NIR spectroscopy in analysis is its dependence on less-precise reference methods. There are four advantages that contribute to the popularity of NIR spectroscopy:

1. It is fast. In addition to the fact that the sample takes very little preparation, a spectrum can be acquired quickly.

2. It is non-destructive. The same sample can be retained for other analytical procedures or returned to the population.

3. It is multi-analytical. More than one constituent can be determined from a single scan or spectrum.

4. It is not dependent on highly skilled personnel to operate the instrumentation.

[9] S.A. Halsey, 'The Use of Transmission and Transflectance Near-Infrared Spectroscopy for the Analysis of Beer', J. Inst. Brew., (1985).

[10] I.J. Wesley, N. Larsen, B.G. Osborne, J.H. Skerritt, 'Non- Invasive Monitoring of Dough Mixing by Near-Infrared spectroscopy', J. Cereal Sci., 27, 61-69 (1998).

[11] T. Fearn, P.I. Maris, 'An Application of BoxJenkins methodology to the Control of Gluten Addition in a Flour Mill', Appl. Statist., 40, 477-484 (1991).

[12] R.C.E. Guy, B.G. Osborne, P. Robert, 'The Application of Near-Infrared Reflectance Spectroscopy to Measure the Degree of Processing in Extrusion Cooking Processes', J. Food Eng., 27, 241258 (1996).

[13] K.H. Norris, P.C. Williams, 'Optimisation of Mathematical Treatments of Raw Near-infrared Signal in the Measurement of Protein in Hard Red Spring Wheat (1984).

[14] M. Manley, A.E.J. McGill, B.G. Osborne, 'The Effect of Light Scattering on NIR Reflectance and Transmittance Spectra of Wheat', J. Near Infrared Spectrosc., 2, 93-99 (1994).

[15] P. Geladi,D. MacDougal,H. Martens, 'Linearization and Scatter Correction for Nearinfrared Reflectance Spectra of Meat', Appl. Spectrosc., 39, 491-500 (1985). 